\title{
Prescribing for painful conditions in adult patients in general practice: A report from the Møre \& Romsdal Prescription Study
}

\author{
Harald A. Nygaard, MD, $\mathrm{PhD}^{1}$, Jørund Straand, $\mathrm{MD}^{2}$ \\ ${ }^{I}$ Division for Geriatric Medicine, Department of Public Health and Primary Health Care,University of Bergen, Norway \\ ${ }^{2}$ Division for General Practice, Department of Public Health and Primary Health Care,University of Bergen, Norway \\ Corresponding author: H. Nygaard, Division for Geriatric Medicine, University of Bergen, Ulriksdal 8c, N-5009 Bergen, Norway \\ Telephone +4755586100 Telefax +4755586130 E-mail Harald.Nygaard@isf.uib.no
}

\begin{abstract}
Study objectives: To analyse the general practitioners' (GPs') prescribing patterns for NSAIDs, muscle relaxants, opioids, compound analgesics with codeine, and plain analgesics, issued for: chronic muskuloskeletal pain, arthritis/osteoarthritis, back pain, headache, casualties, malignancies, and unspecific pain.

Design: A prospective prescription study of analgesics due to painful conditions in the county of Møre \& Romsdal, Norway.

Setting: A one month survey where more than $95 \%$ of the GPs participated and recorded all patient contacts, prescriptions, and diagnoses issued to patients 20 years and over.

Participants: 156 GPs.

Main results: The prescribing rates increased with patients' age to the age group $70-79$ years. $64 \%$ of all prescriptions were for females, who also received more drugs per prescription than males. With increasing patients' age, the average amount of drugs issued per prescription increased, more prescriptions were repeat, and more were issued during indirect GP-patient contacts. The paracetamol/codeine analgesic was the most frequently prescribed drug, $37.6 \%$, followed by NSAIDs (34.6\%) and muscle relaxants $(21.8 \%)$. Plain analgesics were only issued in $2.8 \%$ of the cases. Chronic musculoskeletal pain was the most common diagnostic indication (39.2\%, for which NSAIDs were most frequently prescribed), followed by arthritis/ osteoarthritis (18.7\%), and back pain (18.0\%).

Conclusion: The appropriateness of the GPs prescribing practice for pain often is open to question, and this especially refers to the widespread use of NSAIDs for chronic musculoskeletal pain in the elderly, the frequent use of muscle relaxants for chronic musculoskeletal pain in middle aged women, and the prolonged use of compound analgesics for almost all diagnoses. Plain paracetamol should probably be prescribed more often for pain in general practice.
\end{abstract}

Key words: pain; analgesics; general practice; epidemiology; NSAIDs; paracetamol

\section{INTRODUCTION}

The most frequently prescribed drugs (ATC-system therapeutic groups) in Norway are psycholeptics, analgesics, and non-steroidal anti-inflammatory drugs (NSAIDs), each constituting about $13 \%$ of all prescriptions (1). Sales statistics reveal that analgesic utilisation has increased in Norway during the last decade $(1,2)$, and a corresponding increase has also been shown in Finland (3).

Population studies have shown that increased use of analgesics is associated with female sex, old age, physical activity (for males only), and poor self-perceived health (3-7).

Painful conditions constitute some of the most common reasons for encounter in general practice (8), and prescriptions for pain killers are among the drugs most frequently issued by general practitioners (GPs) (1).
What physicians actually prescribe for various painful conditions is not commonly recognised in the literature. There are only few studies about the GPs' prescribing patterns for various painful conditions $(9,10)$.

The aims of this study were to describe and analyse the GPs' prescribing practice for different pain relieving drugs with respect to patients' age and sex, and the diagnostic indications recorded.

\section{METHODS AND MATERIAL}

This article is a report from the Møre \& Romsdal Prescription Study (MRPS) in which more than 95\% of the 156 GPs in the Norwegian county of Møre \& Romsdal (population aged 20+167,861) recorded all contacts with patients, and all prescriptions issued during November 1988 and November 1989. Details about the MRPS have been described elsewhere 
$(11,12)$. Briefly, during the one month survey the GPs used a specially designed prescription form, a carbon copy of which was retained with a questionnaire. On this copy, the GPs completed data about the kind of GP-patient contact (direct or indirect), the diagnosis for encounter, the diagnostic indication for each prescription, and whether the prescription was initial or repeat. As checked by the pharmacies, the GPs used the MRPS prescription forms in more than $99 \%$ of all prescriptions during the study period (12).

\section{Diagnoses and drugs}

For this study, pain-related diagnoses were clustered in eight groups: chronic musculoskeletal pain, arthritis/ osteoarthritis, back pain, headache excl. migraine, migraine, casualties and outcome after casualties, malignancies, and unspecified pain.

Drugs were classified according to the Anatomical Therapeutic Chemical (ATC) Classification System (13). Prescriptions for the following drugs (ATC codes) were included: NSAIDs (M01), muscle relaxants (M03B), opioids (N02A), other analgesics (N02B). Antimigraine preparations and pain relieving drugs sold over the counter were not included in this survey.

Prescribed amounts were given as Defined Daily Doses (DDD) and DDDs per prescription (DDD/P). One DDD is defined as the assumed average daily dose for the main indication of the drug (13).

\section{Patients and prescriptions}

This study is based on data regarding adult patients aged 20 years and above. The patients were stratified in seven age groups (Table 1).

The numbers of prescriptions were adjusted for age and gender. The population at risk constituted the total population $(169,618$, less 1506 nursing home residents (official and local statistics 1988), amounting 168,112 persons residing in the community, of which $50.3 \%$ were females. Population-based prescribing rate was defined as prescriptions per 100 inhabitants at risk per year.

During the study period the GPs recorded a total of 41,900 contacts of all ages for patients for which 27,970 prescriptions were issued. 9158 of the contacts were with adults $(20+)$ whose reasons for encounter were any of the included diagnoses (Table 2). For the 9158 contacts, 6233 prescriptions were issued, of which 3761 were for drugs in the therapeutic groups included in this study (Table 2). The 3761 prescriptions constitute the material analysed in this article.

\section{Data analysis}

Data were analysed for significant differences using non-parametric methods and $95 \%$ confidence intervals (CI). Prescribing rates by patients' age and sex were studied using logistic regression analysis (14), the various pain-relieving drugs being the dependent variable. The patient age group 20-29 years was chosen as reference group in the regression analyses. The threshold for statistical significance was set at $\mathrm{p} \leq 0.05$.

\section{RESULTS}

Of the 3761 prescriptions, $2406(64 \%)$ were for females. The average age $(95 \% \mathrm{CI})$ of the male patients was significantly lower than that of the females, 49.7 (48.8-50.6) and 52.4 (51.7-53.1) years, respectively.

The population-based prescribing rates were higher for females than for males (Table 1). The mean amount of drugs issued per prescription increased significantly with patients' age (Table 1).

Female patients received on average larger amounts $(95 \% \mathrm{CI})$ of drugs per prescription than men, 25.1 (23.1-27.0) DDD vs. 20.1 (18.6-21.5) DDD.

The prescribing patterns for the different painrelated diagnoses are shown in Table 2 . Thirty per cent

Table 1. Prescriptions for pain relieving drugs for male (M) and female (F) adults in general practice, by: patients' age group, numbers of prescriptions, population based prescribing rates (number of prescriptions per 100 inhabitants at risk ${ }^{\mathrm{a}}$ in the county per year), and mean numbers of Defined Daily Doses (DDDs) per prescription.

\begin{tabular}{|c|c|c|c|c|c|c|c|c|c|c|c|c|}
\hline \multirow{3}{*}{$\begin{array}{l}\text { Age } \\
\text { groups } \\
\text { (years) }\end{array}$} & \multicolumn{4}{|c|}{ Prescriptions } & \multirow{2}{*}{\multicolumn{2}{|c|}{$\begin{array}{l}\text { Population } \\
\text { at risk }^{\mathrm{a}}\end{array}$}} & \multirow{2}{*}{\multicolumn{3}{|c|}{$\begin{array}{l}\text { Prescriptions per } \\
100 \text { persons/year }\end{array}$}} & \multirow{2}{*}{\multicolumn{3}{|c|}{$\begin{array}{l}\text { Mean DDDs } \\
\text { per prescription }\end{array}$}} \\
\hline & \multicolumn{2}{|c|}{ Males } & \multicolumn{2}{|c|}{ Females } & & & & & & & & \\
\hline & $\mathrm{n}=$ & $12 n={ }^{b}$ & $\mathrm{n}=$ & $12 n={ }^{b}$ & $\mathrm{M}$ & $\mathrm{F}$ & $\mathrm{M}$ & $\mathrm{F}$ & $\operatorname{diff}{ }^{c}$ & $\mathrm{M}$ & $\mathrm{F}$ & diff \\
\hline $20-29$ & 175 & 2100 & 244 & 2928 & 18510 & 16147 & 11.5 & 18.1 & ! & 11.0 & 17.4 & - \\
\hline $0-39$ & 284 & 3408 & 405 & 4860 & 17746 & 1639 & 19.2 & 29.6 & ! & 15.0 & 20.6 & - \\
\hline $40-49$ & 248 & 2976 & 473 & 5676 & 14870 & 13697 & 20.0 & 41.4 & ! & 15.6 & 21.8 & ! \\
\hline $50-59$ & 206 & 2472 & 346 & 4152 & 10313 & 10347 & 24.0 & 21.5 & ! & 19.3 & 24.5 & - \\
\hline $60-69$ & 237 & 2844 & 448 & 5376 & 11336 & 12403 & 25.1 & 43.3 & ! & 27.1 & 28.3 & - \\
\hline 70-79 & 154 & 1848 & 358 & 4296 & 7733 & 10087 & 23.9 & 42.6 & ! & 30.2 & 34.4 & - \\
\hline $80+$ & 51 & 612 & 132 & 1584 & 3105 & 5424 & 19.7 & 29.2 & ! & 40.2 & 29.6 & - \\
\hline Total & 1355 & 16260 & 2406 & 28872 & 83613 & 84499 & 19.5 & 34.2 & $!$ & 20.1 & 25.1 & ! \\
\hline
\end{tabular}

${ }^{a}$ the population (corresponding age group) in the county excluding those living in nursing homes.

${ }^{\mathrm{b}}$ Estimated number of prescriptions per year, 12 times the numbers recorded during one month.

${ }^{\mathrm{c}}$ diff: difference between proportions, the $95 \%$ CIs for the proportions do (-) or do not (!) overlap. 
of all prescriptions for NSAIDs were for patients aged 65 or more; the corresponding proportions for muscle relaxants, compound analgesics of paracetamol and codeine, and opioids, were $12 \%, 31 \%$ and $42 \%$, respectively. Of all prescriptions for opioids, dextropropoxyphen comprised $44 \%$, pentazocin $20 \%$, and pethidine (meperidine) $7 \%$.

Prescription rates (odds ratio) for the various diagnoses, and for the different drugs, are shown by patients' age and sex in Tables 3 and 4, respectively. Overall, $43.4 \%$ of the prescriptions were issued during indirect contacts, and $55.5 \%$ were repeat; the proportions of both prescription modes increased with patients' age (Table 5). Repeat prescriptions were on average for larger amounts $(95 \% \mathrm{CI})$ than initial ones: 29.9 (27.6-32.1) vs. 15.3 (14.0-16.6) DDDs. Correspondingly, prescriptions issued during indirect contacts were on average for more drugs $(95 \% \mathrm{CI})$ than those prescribed during face-to-face contacts: 27.1 (24.4-29.7) vs. 20.1 (18.7-21.4) DDDs/P. The average prescribed amount (DDDs/P) $(95 \% \mathrm{CI})$ varied between the different drugs: NSAIDs, 32.9 (30.7-35.1); muscle relaxants, 14.1 (12.8-15.4); opioids, 25.3 (20.5-30.0); plain analgesics, 20.4 (15.6-25.2); and compound analgesics with codeine, 19.8 (17.0-22.5).

\section{DISCUSSION}

To our knowledge, there are no evidence-based comprehensive guidelines for the appropriate use of drugs for relieving pain in patients in general practice. Guidelines for the treatment of painful conditions generally do not take into account that pain is a personal experience and that treatment should reflect this (15). Hence therapeutic choices are influenced by individual characteristics of the patients (e.g. age), and the physician's prescribing habits and knowledge about the side effects of the drugs.

Although the medical and welfare systems are fairly comparable in the Nordic countries, there are notable differences in the uses of different drugs for pain. In terms of numbers of DDDs sold per 1000 inhabitants per day, sales statistics show that compared with Norway, the Finnish population use twice the amount of NSAIDs, in Sweden they use four times more opioids (ATC system class N02A), while in

Table 2. Number of prescriptions for the pain related diagnoses by drug prescriptions (therapeutic groups) and the total Defined Daily Doses (DDDs) prescribed.

\begin{tabular}{|c|c|c|c|c|c|c|c|c|c|}
\hline \multirow{3}{*}{$\begin{array}{l}\text { Diagnostic } \\
\text { groups }\end{array}$} & \multicolumn{5}{|c|}{ Drug prescriptions (therapeutic ATC groups) } & \multirow[b]{2}{*}{$\mathrm{Su} \mathrm{m}$} & \multicolumn{3}{|c|}{ Defined Daily Doses } \\
\hline & \multirow[b]{2}{*}{ NSAIDs } & \multirow{2}{*}{$\begin{array}{c}\text { Muscle } \\
\text { relaxants }\end{array}$} & & \multirow{2}{*}{$\begin{array}{l}\text { Paracetamol/ } \\
\text { codeine }^{\mathrm{a}}\end{array}$} & \multirow{2}{*}{$\begin{array}{c}\text { Plain } \\
\text { analgesics }^{\mathrm{b}}\end{array}$} & & & & \\
\hline & & & Opioids & & & $\mathrm{n}=(\%)$ & $\mathrm{n}=$ & $(\%)$ & $\mathrm{DDD} / \mathrm{P}$ \\
\hline Chronic musculoskeletal pain & in 582 & 464 & 26 & 377 & 27 & $1,476 \quad(39.2)$ & 26,287 & $(30.1)$ & 17.8 \\
\hline Arthritis/osteoarthritis & 476 & 20 & 14 & 169 & 23 & 702 (18.7) & 34,467 & $(39.4)$ & 49.1 \\
\hline Back pain & 96 & 267 & 13 & 288 & 11 & $675(18.0)$ & 9,768 & $(11.2)$ & 14.5 \\
\hline Headache & 5 & 39 & 5 & 115 & 8 & $172 \quad(4.6)$ & 3,574 & (4.1) & 20.2 \\
\hline Casualties & 32 & 4 & 5 & 77 & 3 & (3.2) & 1,275 & (1.5) & 10.5 \\
\hline Migraine & 25 & 4 & 6 & 57 & - & $(2.4)$ & 3,115 & (3.6) & 33.9 \\
\hline Unspecified pain & 83 & 22 & 44 & 317 & 29 & 495 (13.2) & 8,249 & (9.4) & 16.7 \\
\hline Malignancies & 1 & 0 & 10 & 14 & 3 & $28 \quad(0.7)$ & 814 & $(0.9)$ & 29.1 \\
\hline $\mathrm{n}=$ & 1,300 & 820 & 123 & 1,414 & 104 & $3,761(100.0)$ & 87,449 & $(100.0)$ & 23.3 \\
\hline$\%$ & 34.6 & 21.8 & 3.3 & 37.6 & 2.8 & 100.0 & & & \\
\hline DDDs & 42,734 & 11,544 & 3,106 & 27,943 & 2,122 & 87,449 & & & \\
\hline DDDs $\%$ & 48.9 & 13.2 & 3.5 & 32.0 & 2.4 & 100.0 & & & \\
\hline Mean DDD/P & 32.9 & 14.1 & 25.3 & 19.8 & 20.4 & 23.3 & & & \\
\hline
\end{tabular}

${ }^{a}$ Compound analgesic with paracetamol and codeine

${ }^{\mathrm{b}}$ Paracetamol, 68; phenazone preparations, 23; diflunisal, 9; aspirin, 4

Table 3. Logistic regression analysis showing odds ratio (OR) for adult patients to receive any pain relieving drug depending on the diagnosis for encounter.

\begin{tabular}{|c|c|c|c|c|c|c|c|c|}
\hline $\begin{array}{l}\text { Age } \\
\text { groups } \\
\text { (years) }\end{array}$ & $\begin{array}{l}\text { Chronic musculo- } \\
\text { skeletal pain } \\
\mathrm{n}=1476 \\
\text { OR }(95 \% \mathrm{CI})\end{array}$ & $\begin{array}{l}\text { Arthritis/ } \\
\text { osteoarthritis } \\
\mathrm{n}=702 \\
\text { OR }(95 \% \mathrm{CI})\end{array}$ & $\begin{array}{l}\text { Back pain } \\
\mathrm{n}=675 \\
\text { OR }(95 \% \mathrm{CI})\end{array}$ & $\begin{array}{l}\text { Headache } \\
\mathrm{n}=172 \\
\text { OR }(95 \% \mathrm{CI})\end{array}$ & $\begin{array}{l}\text { Casualties } \\
\mathrm{n}=121 \\
\text { OR }(95 \% \mathrm{CI})\end{array}$ & $\begin{array}{l}\text { Migraine pain } \\
\mathrm{n}=92 \\
\text { OR }(95 \% \mathrm{CI})\end{array}$ & $\begin{array}{l}\text { Unspecified } \\
\mathrm{n}=495 \\
\text { OR }(95 \% \mathrm{CI})\end{array}$ & $\begin{array}{l}\text { Malignancies } \\
\mathrm{n}=28 \\
\text { OR }(95 \% \mathrm{CI})\end{array}$ \\
\hline $20-29$ & Reference & Reference & Reference & Reference & Reference & Reference & Reference & Reference \\
\hline $30-49$ & $1.9(1.6-2.3)$ & $2.5(1.7-3.7)$ & $1.9(1.5-2.4)$ & $1.5(0.98-2.4)$ & $0.8(0.5,1.4)$ & $1.7(0.9-2.9)$ & $2.0(1.5-2.7)$ & $2.8(0.3-23.7)$ \\
\hline $50-69$ & $2.1(1.8-2.5)$ & $6.9(4.7-10.1)$ & $2.0(1.5-2.5)$ & $1.1(0.7-1.7)$ & $1.0(0.6,1.7)$ & $1.2(0.6-2.2)$ & $1.9(1.4-2.6)$ & $9.4(1.2-72.1)$ \\
\hline $70-79$ & $1.6(1.3-2.0)$ & $10.4(7.1-15.3)$ & $1.0(0.7-1.4)$ & $1.4(0.8-2.5)$ & $0.98(0.5,1.9)$ & $0.2(0.05-0.9)$ & $2.7(1.9-3.9)$ & $9.7(1.1-83.5)$ \\
\hline $80+$ & $0.7(0.5-1.1)$ & $8.5(5.6-13.1)$ & $0.9(0.6-1.5)$ & $0.4(0.1-1.3)$ & $0.95(0.4,2.3)$ & $<0.00003$ & $2.9(1.9-4.4)$ & $8.2(0.7-90.3)$ \\
\hline Females & $1.9(1.7-2.1)$ & $2.0(1.7-2.4)$ & $1.2(0.99-1.3)$ & $2.0(1.4-2.8)$ & $0.95(0.7-1.4)$ & $4.3(2.6-7.2)$ & $1.9(1.5-2.3)$ & $0.98(0.4-2.2)$ \\
\hline
\end{tabular}


Table 4. Logistic regression analysis showing odds ratio $(\mathrm{OR})$ for adult patients to receive different pain relieving drugs.

\begin{tabular}{|c|c|c|c|c|c|c|}
\hline $\begin{array}{l}\text { Age } \\
\text { groups } \\
\text { (years) }\end{array}$ & $\begin{array}{l}\text { NSAIDs } \\
\mathrm{n}=1300 \\
\text { OR }(95 \% \mathrm{CI})\end{array}$ & $\begin{array}{l}\text { Muscle } \\
\text { relaxants } \\
\mathrm{n}=820 \\
\text { OR }(95 \% \mathrm{CI})\end{array}$ & $\begin{array}{l}\text { Opioids } \\
\mathrm{n}=123 \\
\text { OR }(95 \% \mathrm{CI})\end{array}$ & $\begin{array}{l}\text { Compound } \\
\text { analgesics } \\
n=1414 \\
\text { OR }(95 \% \mathrm{CI})\end{array}$ & $\begin{array}{l}\text { Plain } \\
\text { analgesics } \\
\mathrm{n}=104 \\
\text { OR }(95 \% \mathrm{CI})\end{array}$ & $\begin{array}{l}\text { Any } \\
\text { pain killer } \\
\mathrm{n}=3761 \\
\text { OR }(95 \% \mathrm{CI})\end{array}$ \\
\hline $20-29$ & Reference & Reference & Reference & Reference & Reference & Reference \\
\hline $30-49$ & $1.4(1.2-1.7)$ & $2.0(1.7-2.5)$ & $5.0(1.8-14.0)$ & $2.2(1.8-2.7)$ & $1.5(0.7-3.4)$ & $1.9(1.7-2.1)$ \\
\hline $50-69$ & $1.9(1.6-2.3)$ & $1.5(1.1-1.9)$ & $9.2(3.3-25.5)$ & $3.1(2.5-3.7)$ & $3.5(1.6-7.5)$ & $2.3(2.0-2.6)$ \\
\hline $70-79$ & $2.0(1.7-2.5)$ & $0.8(0.6-1.1)$ & $12.1(4.2-34.9)$ & $3.4(2.7-4.2)$ & $6.6(3.0-14.4)$ & $2.2(2.0-2.6)$ \\
\hline $80+$ & $1.5(1.1-2.0)$ & $0.6(0.4-0.96)$ & $11.1(3.5-35.1)$ & $2.4(1.8-3.2)$ & $3.6(1.4-9.6)$ & $1.6(1.4-2.0)$ \\
\hline Females & $1.6(1.5-1.8)$ & $2.0(1.6-2.4)$ & $1.02(0.7-1.5)$ & $1.7(1.6-1.9)$ & $2.1(1.4-3.3)$ & $1.8(1.6-1.9)$ \\
\hline
\end{tabular}

Table 5. Prescribing practice for analgesics in general practice for different age groups by type of prescriptions (initial or repeat), type of contact (direct or indirect), and odds ratio (OR) with 95\% confidence intervals $(95 \% \mathrm{CI})$ for repeat prescriptions and indirect contacts, respectively.

\begin{tabular}{|c|c|c|c|c|c|c|}
\hline \multirow{3}{*}{$\begin{array}{l}\text { Age } \\
\text { group } \\
\text { (years) }\end{array}$} & \multicolumn{3}{|c|}{ Type of prescription, } & \multicolumn{3}{|c|}{ Type of contact ${ }^{\mathrm{c}, \mathrm{d}}$} \\
\hline & \multirow{2}{*}{$\frac{\text { Initial }}{\%}$} & \multicolumn{2}{|c|}{ Repeat } & \multirow{2}{*}{$\frac{\text { Direct }}{\%}$} & \multicolumn{2}{|r|}{ Indirect } \\
\hline & & $\%$ & OR $(95 \% \mathrm{CI})$ & & $\%$ & OR $(95 \% \mathrm{CI})$ \\
\hline $20-29$ & 67 & 33 & Reference & 67 & 33 & Reference \\
\hline $30-49$ & 48 & 52 & $2.1(1.7-2.7)$ & 58 & 42 & $1.5(1.2-1.9)$ \\
\hline $50-69$ & 41 & 59 & $2.9(2.3-3.7)$ & 54 & 46 & $1.7(1.4-2.2)$ \\
\hline $70-79$ & 31 & 69 & $4.6(3.4-6.0)$ & 54 & 46 & $1.8(1.3-2.3)$ \\
\hline $80+$ & 29 & 71 & $4.8(3.3-7.1)$ & 47 & 53 & $2.3(1.6-3.7)$ \\
\hline Total & 45 & 55 & & 57 & 43 & \\
\hline $\mathrm{n}=$ & 1546 & 1925 & & 2022 & 1552 & \\
\hline
\end{tabular}

${ }^{\text {a }}$ Incomplete data initial or repeat prescription in 290 cases

${ }^{\mathrm{b}}$ Linear trend $\chi^{2}=131.0, \mathrm{df}=1, \mathrm{p}<0.0001$

${ }^{\mathrm{c}}$ Incomplete data regarding type of contact in 187 cases

${ }^{\mathrm{d}}$ Linear trend $\chi^{2}=23.6, \mathrm{df}=1, \mathrm{p}<0.0001$

Denmark they use two times the amount of analgesics in the ATC class N02B (16). Because the treatments for pain vary so widely, both within Norway (1) and between the Nordic countries, this should be taken into consideration when interpreting our data. Furthermore, the utilisation of the examined drugs in Norway have undergone changes since our data were recorded. From 1988 to 1995 the retail volume (DDD/1000 inhabitants/day) of NSAIDs increased by $28 \%$, whereas the use of muscle relaxants decreased by $36 \%$ (1).

NSAIDs are primarily recommended for painful conditions in which an inflammatory component is supposed to be present (e.g. arthritis), but were in this study also widely issued for chronic and degenerative conditions in which the inflammation is less pronounced (e.g. chronic musculoskeletal pain). Our data on the amount of NSAIDs issued for pain correspond well with Norwegian sales statistics from 1988, which reveal that NSAIDs constituted about $50 \%$ of the purchased DDDs of the drugs assessed here (2). Our finding that about two of five prescriptions for chronic musculoskeletal pain were for NSAIDs contradicts the message that other drugs should be preferred because they may relieve the pain as effectively but with less gastrointestinal side effects $(17,18)$. This is of special relevance for elderly patients, in whom serious adverse effects and interactions with NSAIDs are more frequent $(19,20)$. For the society, the costs of the NSAIDinduced gastrointestinal side effects correspond to about half the cost of the NSAIDs (21). Their simple administration (e.g. once or twice daily) is one possible explanation for the popularity of the NSAIDs, another may be that they are reimbursed by the national Norwegian health insurance program, whereas analgesics and muscle relaxants are not.

Muscle relaxant preparations were mainly found to be prescribed for middle aged women with chronic musculoskeletal pain. Muscle relaxants are generally compound drugs with analgesics (e.g. paracetamol). Evidence, based on well designed studies, on possible advantages of these drugs over plain analgesics are scarce. In one review (22), their effects were found to be superior over placebo in acute musculoskeletal conditions, but not for chronic conditions. The most appropriate use of muscle relaxants appears to be for acute pain associated with spasms (23). According to this, the appropriateness of most prescriptions for muscle relaxants examined in this study, is open to question. In Norway, several of the muscle relaxant preparations have been withdrawn from the market since our data were recorded, and the utilisation of these drugs has declined (1).

Opioids are indicated for the symptomatic treatment of moderate or more severe pain. The prescriptions of opioids was almost insignificant in this study, but they covered all therapeutic indications included. There is a general agreement in recommending opioids for severe pain in cancer, when alternatives are insufficient. The prolonged use of opioids for non-malignant pain remains controversial. GPs and rheumatologists probably have a more pragmatic attitude towards their uses than other physicians (24). Opioids should probably be tried more often for non-malignant pain when other treatments have failed (15). However, propoxyphene and pethidine are in general not recommended for elderly patients (25). In our survey, these were the most commonly issued opioids, also for the elderly.

In terms of numbers of prescriptions, we found that the compound analgesic with paracetamol and codeine was the most frequently prescribed drug, and number two in terms of amount (DDDs). Except for musculo- 
skeletal pain and arthritis/osteoarthritis, paracetamol/ codeine was the dominating pain modifying drug. In single dose studies, the analgesic effects of paracetamol with codeine have been found to be significantly somewhat better than paracetamol alone (26). This compound analgesic represents the second step of the WHO "analgesic ladder" for cancer pain, and they are effective in postoperative pain (15). However, their superiority in chronic pain is equivocal. KjærsgaardAndersen et al. (27) compared paracetamol (3000 mg a day) with and without codeine (180 $\mathrm{mg}$ a day) in elderly patients with osteoarthritis of the hip and showed that the compound analgesics were superior to paracetamol only during the first week of treatment, later on there were no significant differences. However, those who received the compound analgesics suffered significantly more adverse drug reactions, and the authors concluded that the addition of codeine cannot be recommended for longer-term treatment of chronic pain in elderly patients. Bushnell and Justins (15) claim also that chronic pain patients have little additional benefit from the compound drug, and that their use therefore should be carefully assessed.

\section{Patients' age and sex}

Similar to the findings of other studies $(4,8)$, the probability for receiving a prescription for a pain relieving drug was significantly higher for females, and there was also a significant age-related increase in the numbers of prescriptions. This age-related increase in the use of analgesics fits well with the findings of others $(7,28)$. Applying the present logistic regression method on the published data from Eggen and Andrew (5) gave comparable results to our own, except for a higher odds ratio for patients aged 80 and over in their study. Eggen, who also included OTC analgesics, did not report this age-related trend in her paper (6).

\section{Contacts}

The proportion of prescriptions issued during indirect contacts as repeat prescriptions may seem high especially for the elderly patients. We have no other studies for comparison here, but this phenomenon may reflect the high prevalence of chronic illness and reduced mobility among the elderly. On the other hand, it may represent inappropriate prescribing practice if clinical controls are not performed because the GPs omit to assess the patients at regular intervals (29).

\section{Limitations}

A possible limitation of the external validity is that there were no explicit criteria for the diagnoses.
Another may be caused by our clustering of diagnoses into diagnostic groups. However, we believe that the diagnoses used here, are quite representative for the use of diagnoses during everyday practice.

The distribution of diagnoses reported here, does not necessarily reflect the true prevalence of pain complaints in the population. However, the prescription patterns for the different diagnoses correspond well with findings in different prevalence studies (30-32). Furthermore, the distribution of the indications for prescribing the pain relieving drugs are in line with figures in a Danish study apart from the higher proportion of prescriptions for malignancies in that study (33).

In this study we did not have any data on comorbidity or on social conditions which in individual patients often interfere both with their patterns of seeing physicians, and with the kind of prescriptions they receive.

The main strength of this study is the high internal validity because almost all GPs participated in the survey and they complied well in using the MRPS prescription forms $(11,12)$.

\section{CONCLUSIONS}

Our findings suggest that the appropriateness of the GPs' prescribing practice for painful conditions is open to question, and this applies especially to the widespread use of NSAIDs for chronic musculoskeletal pain in the elderly, the frequent use of muscle relaxants for chronic musculoskeletal pain in middle aged women, and the prolonged use of compound analgesics for almost all diagnoses where plain paracetamol in adequate dosage probably would have been more appropriate. The almost non-existing prescribing of paracetamol suggests that GPs in general bypass use of this well documented drug for chronic pain. In Norway, paracetamol is mainly issued in small quantities (in packages with less than 5DDDs) that are sold OTC. It is a general impression that lay persons often assume that prescribed analgesics are more effective than those sold OTC. By not prescribing paracetamol the GPs strengthen this assumption, which they instead should try to counteract.

\section{ACKNOWLEDGEMENT}

We thank Kirsten Rokstad for her important contributions in running the main survey of the Møre \& Romsdal Prescription Study during 1988 and 1989, and for her initial work with the data. We thank Rolf Skjærven for statistical advice during the preparation of this manuscript. Finally, we thank all the GPs in Møre \& Romsdal for their help in providing the data.

\section{REFERENCES}

1. Øydvin K (ed). Legemiddelforbruket i Norge 1991-1995. Oslo: Norsk Medisinaldepot, 1996.

2. Øydvin K (ed). Legemiddelforbruket $i$ Norge 1989-1993. Oslo: Norsk Medisinaldepot, 1994.

3. Ahonen R, Klaukka T, Martikainen J, Enlund H. Use of analgesics and inflammatory drugs in Finland: a cross-sectional analysis in 1976 and 1987. J Soc Adm Pharm 1993; 10: 15-22. 
4. Boëthius G. Recording of drug prescriptions in the county of Jämtland, Sweden. Acta Med Scand 1977; 202: 241-51.

5. Eggen AE, Andrew M. Use of codeine analgesics in a general population: a Norwegian study of moderately strong analgesics. Eur J Clin Pharmacol 1994; 46: 491-6.

6. Eggen AE. The Tromsø study: Frequency and predicting factors of analgesic drug use in a free-living population (12-56 years). J Clin Epidemiol 1994; 46: 1297-1304.

7. Antonov K, Isacson D. Use of analgesics in Sweden. The importance of sociodemographic factors, physical fitness, health and health-related factors, and working conditions. Soc Sci Med 1996; 42: 1473-81.

8. Frølund F, Nyrop-Larsen T. Lægemiddelordinationer i almen praksis I. Ni lægers ordinationsmønster i to 3måneders perioder i $1975 \mathrm{og}$ 1976. Ugeskr Loeg 1979; 141: 1509-14.

9. Gustafsson LL, Boëthius G. Utilization of analgesics from 1970 to 1978. Prescription patterns in the county of Jämtland and in Sweden as a whole. Acta Med Scand 1982; 211: 419-25.

10. Keys J, Beardon PHG, Lau C, Lang CC, McDevitt DG. General practitioners' use of non-steroidal antiinflammatory drugs in Tayside and Fife regions. $J$ R Soc Med 1992; 85: 442-5.

11. Rokstad K, Straand J, Fugelli P. Can drug treatment be improved by feedback on prescribing profiles combined with therapeutic recommendations? A prospective, controlled trial in general practice. $J$ Clin Epidemiol 1995; 48: 1061-8.

12. Rokstad K, Straand J. General practitioners' drug prescribing practice and diagnoses for prescribing: The Møre \& Romsdal prescription study. J Clin Epidemiol 1997; 50: 485-94.

13. Guidelines for ATC-classification. WHO collaborating centre for drug statistics methodology and Nordic Council on Medicines. Oslo/Uppsala, 1990.

14. Dixon WJ. BMDP Statistical Software. Berkeley: University of California Press, 1988.

15. Bushnell TG, Justins DM. Choosing the right analgesic. A guide to selection. Drugs 1993; 46: 394-408.

16. Nordic Statistics on Medicines 1990-1992. Uppsala: Nordic Council on Medicines, NLN publication No. 34 , 1993.

17. Bradley JD, Brandt KD, Katz BP, Kalasinski LA, Ryan SI. Comparison of an antiinflammatory dose of ibuprofen, an analgesic dose of ibuprofen, and acetaminophen in the treatment of osteoarthritis of the knee. $N$ Engl J Med 1991; 325: 87-91.

18. Dieppe PA, Frankel SJ, Toth B. Is research into the treatment of osteoarthritis with non-steroidal antiinflammatory drugs misdirected? Lancet 1993; 341: 353-4.

19. Laporte JR, Carne X, Vida X, Morena M, Juan J. Upper gastrointestinal bleeding in relation to previous use of analgesics and non-steroidal anti-inflammatory drugs. Lancet 1991; 337: 85-9.

20. Bateman DN, Kennedy JG. Non-steroidal anti-inflammatory drugs and elderly patients. The medicine may be worse than the disease. BMJ 1995; 310: 817-8.

21. Bloom BS. Direct medical costs of disease and gastro-intestinal side-effects during treatment for arthritis. Am J Med 1988; Suppl 2A: 20-4.

22. Elenbaas JK. Centrally acting oral skeletal muscle relaxants. Am J Hosp Pharm 1980; 37: 1313-23.

23. Balano KB. Anti-inflammatory drugs and myorelaxants. Pharmacology and clinical use in musculoskeletal disease. Prim Care 1996; 23: 329-34.

24. Turk DC, Brody MC, Okifuji A. Physicians' attitudes and practices regarding the long-term prescribing of opioids for non-cancer pain. Pain 1994; 59: 201-8.

25. Forman WB. Opioid analgesic drugs in the elderly. Clin Geriatr Med 1996; 12: 489-500.

26. de Craen AJM, Giulio GD, Lampe-Schoenmaeckers AJEM, Kessels AGH, Kleijnen J. Analgesic efficacy and safety of paracetamol-codeine combinations versus paracetamol alone: a systematic review. $B M J 1996 ; \mathbf{3 1 3}$ : $321-5$.

27. Kjærsgaard-Andersen $\mathrm{P}$, Nafei A, Skov O, et al. Codeine plus paracetamol versus paracetamol in longer-term treatment of chronic pain due to osteoarthritis of the hip. A randomised, double-blind, multi-centre study. Pain 1990; 43: 309-18.

28. Ahonen R, Enlund H, Pakarinen V, Riihimäki S. A 1-year follow-up of prescribing patterns of analgesics in primary health care. J Clin Pharm Ther 1992; 17: 43-7.

29. Anonymous (Editorial). Need we poison the elderly so often? Lancet 1988; ii: 20-2.

30. von Korff M, Dworkin SF, Le Resche L, Kruger A. An epidemiological comparison of pain complaints. Pain 1988; 32: 173-83.

31. James FR, Large RG, Bushnell JA, Wells JE. Epidemiology of pain in New Zealand. Pain 1991; 44: 279-83.

32. Natvig B, Nessiøy I, Bruusgaard D, Rutle O. Muskel- og skjelettplager i en befolkning. Forekomst og lokalisasjon. Tidsskr Nor Lageforen 1994; 114: 323-7.

33. Sørensen HT, Rasmussen HH, Møller-Petersen JF, Ejlersen E, Hamburger H, Olesen F. Epidemiology of pain requiring strong analgesics outside hospital in a geographically defined population in Denmark. Dan Med Bull 1992; 39: 464-7. 